\title{
The Impact of MOOCs on College English Reform in Mainland China
}

\author{
Min Cao \\ School of Foreign Language Studies, Henan Polytechnic University, Jiaozuo, Henan, China; \\ School of Languages, University of Portsmouth, UK
}

\begin{abstract}
Massive Open Online Courses (MOOCs) are internationally accepted as a popular online learning, its introduction into Mainland China provides an opportunity for College English education reform, which is on progress since 2007. This article attempts to draw a picture of College English teaching reform under the influence of MOOCs by adopting documentary research method through analyzing all the essays about College English teaching under the wave of MOOCs in CNKI (China National Knowledge Infrastructure) according to their research contents. The data collected shows that theoretically College English teaching could be reformed by taking the form of MOOCs in the courses of English for general purposes (EGP), English for general education (EGE), and English for specific purposes (ESP). It seems that during the reform teaching models and student-teacher relationship are altered by the MOOCs environment. Additionally, College English courses on several MOOCs platforms are analyzed, they further prove the practical College English courses done on MOOCs platforms. This paper seems to throw light on a general overview of College English teaching in Mainland China for English teachers and researchers and propose further improvement for college English teaching reform.
\end{abstract}

Index Terms-MOOCs, College English reform, teaching content, teaching model, student-teacher relationship

\section{INTRODUCTION}

College English, one of the obligatory courses in Chinese universities, has been undergoing reforms ever since the beginning of 21 century. In 2007, Chinese Ministry of Education (MOE) notified College English Curriculum Requirements (CECR), in which it is indicative that 'All universities should adopt modern technology, especially computer and classroom based teaching model in their College English teaching models to supplement the teachercentered single-type teaching model. These new teaching models should build on modern information technology, particularly network technology to ensure College English learning free from time and place restrictions, which develop into those classes facilitate students' autonomous and individualized learning.' (2007, p.18) Ever since then, all of the Chinese universities have adopted the blended teaching and learning model based on network and classroom instruction, which shows that College English has succeeded in reforming its teaching model. Lately, a new means of online learning MOOCs started budding in 2008, and expanded worldwide in 2012. The year 2012 was marked as 'the year of MOOC' by New York Times, MOOC appeared as a new means of online learning provides opportunity for all the users online with no 'boundaries of learning institutions' (Kop et al., 2011a; De Witt et al., 2014; Norman et al., 2014). Within the past four years, MOOCs have developed into massive open education resources. During this international open education resources movement, a great number of top universities and organizations participated in, for example, the three most notable MOOC platforms Coursera, edX, Udacity (Alraimi et al., 2015) and Khan Academy in United States, FutureLearn in the United Kingdom, unX in Spain.

Meanwhile, the concept of MOOC was brought into Mainland China, a great number of MOOCs platforms have been built up. For instance, xuetangx.com, as the first MOOC in Mainland China, was sponsored by Tsinghua University and collaborated with Zhejing University and Nanjing University, now grow into one of the most popular MOOCs in Mainland China. Other similar platforms are CNMOOC, University Open Online Courses (UOOC) and WEMMOOC. This paper tries to present an overview of the status of college English teaching under the wave of MOOC in Mainland China by teasing all the essays recently published in CNKI according to their research contents and research methods.

\section{COLLEGE ENGLish EduCATION UNDER MOOCS}

\section{A. Data Collection}

In this article, the data used for analyzing is collected by browsing for 大学英语慕课 (the Chinese corresponding translation for College English MOOCs) in CNKI. There are 162 papers published before the data was collected in October, 2016. After reading through each paper, nearly 129 papers are closely related with College English under the wave of MOOCs in Mainland China. The following paper tries to analyze the research content in those published papers, 
the present status of College English education under MOOCs will be further discussed. From Figure.1, it can be seen that the number of papers about College English under the wave of MOOCs started to appear in 2013, and increased in 2014 and 2015, grew abruptly in 2016 before October when the data was collected, which shows that the increasing group of English teachers and researchers who give their attention to the development and changes of College English with the great impact of MOOCs.

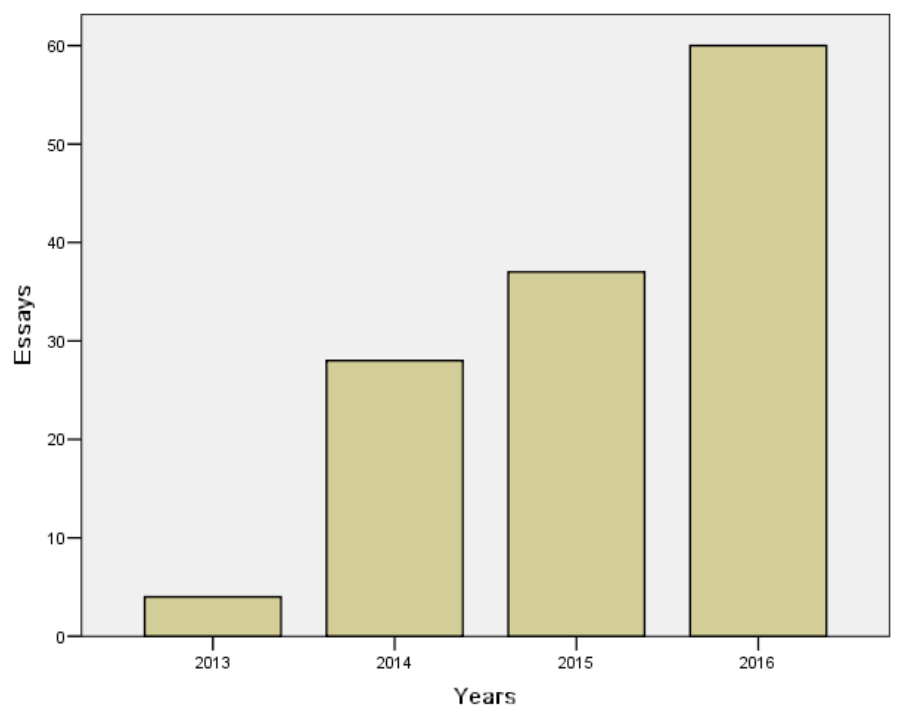

Figure 1. The number of papers in publication year

\section{B. The Topic Issues in Researches}

When reading through the 129 papers about College English under the influence of MOOCs, they could be generally classified into qualitative researches and quantitative researches based on the research method taken in the papers. Some popular topic issues stand revealed on College English education in those papers are its prospects and challenges brought by MOOCs, redesign of its content, teaching model and changes to teachers' roles in College English teaching.

(1). Prospects and challenges brought by MOOCs on College English

When MOOCs first brought into China, the impact of international MOOCs was expected by some researchers in Mainland China, such as, Ma \& Hu (2014) stated that there would be challenges and opportunities for College English, and proposed the reconstruction of College English Curriculum by using the concept of MOOCs. Xiong (2016) claimed that, on one hand, MOOCs resources have enriched teaching materials and lowered the production costs of College English course, on the other hand, MOOCs has brought about changes to the approaches of College English classroom teaching so as to satisfy individual difference on the part of the students. In this way, MOOCs challenges the traditional approaches of College English teaching and learning, during which the relations between teachers and students can be changed. So for both of them MOOCs are innovative concept and technology, only when they get fully involved in can MOOCs be fully utilized. Xie (2015) and Zhang (2015) expressed similar understanding of the changes brought by MOOCs, which have altered the input-dominated classroom teaching model, renewed the content of traditional paper textbooks and changed the asymmetrical teacher-student relationship.

(2). Teaching content

Hutchison \& Waters (1987) stated that teaching English as a foreign language could be divided into EGP (English for General Purposes) and ESP (English for Specific Purposes). The latter was further classified into EAP (English for Academic Purposes) and EOP (English for Occupational Purpose). There is heated discussion about the reconstruction of College English content in Mainland China, one group of researchers represented by Professor Jigang Cai (2013), who advocated that College English should be taught as EAP, while another group stressed that College English should go as EGP and EGE (English for General Education). Up to now, it reached an agreement that College English should consist of EGP and follow-up courses which is composed of ESP and EGE (Wang, 2013). EGP stresses basic English knowledge to improve students' language skills such as listening, speaking, reading, writing and translation abilities. While ESP teaching is the combination of English with specific field, such as Business English, Financial English and Accounting English.

Ma \& Hu (2014) claimed that one of the opportunities MOOCs brought to College English is to reconstruct its teaching content according to students' study needs. For those students in top universities as good English learners, they should be given courses as Academic English as one obligatory course to help them transfer to international MOOCs, bilingual courses, and intercultural communication as one selected course. For those students in average universities, on one hand, their English skills should be improved through General English courses, on the other hand, their abilities of using English for academic purpose and intercultural communication should be cultivated according to their own needs. 
For the application of MOOCs in College English, Chen (2016) claimed that only limited aspects could combine MOOCs with foreign language learning at the elementary period, mainly in writing. It is further stated that the advantages of MOOCs could be better exploited only in the advanced learning period, in which learners' thought sparks by communicating with each other and their thinking ability and creativity could be fostered, particularly written translation ability.

\section{A. EGP}

Among 129 papers collected, there are 14 papers discuss the development of students' language skills i.e. listening, speaking, writing and translation. Han (2016) reported the construction of MOOCS about English listening practice through inputting news and reports selected from VOA, BBC and CNN. This MOOCs is arranged with objective, study, quiz, learning with companions and exchange learning experience five parts of contents, which emphasizes autonomous learning with clear learning objective, monitoring the learning process by following students' study and quizzes and learning from their peers. Zhang (2015) studied the design and practice of MOOCs for spoken English teaching and learning with the case of "English 900 in MOOCs", including its background and significance, objectives and concepts, development procedures, technological requirements, target learner, teachers, course structure, linguistic input and output, time distribution, etc. The study is expected to enrich MOOCs paradigms for spoken foreign language, and promote the development of MOOCs for foreign language teaching and learning. Sun (2016) explored the strategies to promote the College English translation teaching by analyzing the subjective and objective factors influence College English translation teaching in MOOCs era. It is suggested that students' translation skills could be improved mainly through cultivating translation skills in reading teaching and learning as well as practical translation training. Wang (2016) analyzed the deficiencies of traditional College English translation teaching and proposed the construction of the courses of college English translation in the era of MOOCs.

\section{B. ESP}

Zhao \& Wang (2016) claimed that the widespread of MOOCs provide rich material for ESP teaching. Similarly, Liu (2016) stated that MOOCs bring great number of good-qualified teaching material which promises ESP teaching and learning. Dong \& Li (2014) proposed practical strategies of reforming the present Medical English teaching with help of MOOCs after analyzing deficiencies of the traditional medical English classroom instruction. Wang et. al (2015) conducted qualitative as well as quantitative research by carrying out a practical teaching experiment with the idea of "on-line MOOC courses + CBI(Content-based Instruction ) + ESP "(MCE), which proves the validity of this MCE teaching model on the improvement of learners' learning motivation, learning strategies, and English proficiency. Similar research was done by Ren \& Guan (2016) through making use of MOOCs platform courses and practical ESP learning, results showed that students' motivation and interest of learning English have been activated, their learning proficiency especially listening and vocabulary understanding has been improved significantly.

(3) Teaching model: Flipped classroom, Micro-course or Mini-course

\section{A. Micro-course}

The term micro-lecture or mini-lecture, first proposed by David Penrose, emerged as short videos for online and mobile learning. With the popularity of micro-lecture in Mainland China micro-lecture is defined as a less than ten minutes video concentrating on one topic in teaching objectives. Its potential of becoming a successful practice in large campus courses was cultivated in Mainland China. Yan (2014) explained the features of English grammar points, reading and writing strategies, translation skills, listening and oral performance and analyzed the teaching strategies implied in College English micro-lecture by combining with three slices of teaching design. Sun (2016) discussed micro-lecture design about translation in National College English Test Band 4. Those micro-lectures could not only save the teachers and students' time to discuss theoretical points in class but also help students learn about the translation skills at their spare time.

\section{B. Blended learning}

Different from the traditional face-to-face classroom, blended learning is a relatively new term which commonly means that blended learning environment combine face-to-face instruction with technology-meditated instruction (Graham, 2005; Graham et al., 2003). With the popularity of MOOCs online courses, blended learning model is introduced into College English teaching. For the blended learning in College English teaching, there are two kinds of blendings exist, one is the combination of traditional face-to-face instruction with computer-mediated instruction, the other is flipped classroom with computer-mediated instruction.

a. Traditional face-to-face instruction

Zhou (2016) introduced the model of blended instruction that it complements the weaknesses of MOOCs with traditional face-to-face instruction. The characteristics of its application into College English teaching is explored in terms of seven aspects, i.e. students, teaching objectives, teaching content, teaching methods, teaching environment, feedback and teachers. Sun \& Wei (2016) discussed the blended teaching model driven by MOOCs and Corpus and analyzed its application in College English, the survey showed that the two together can make full use of information technology and college English blended teaching and its potential. Chen \& Wang (2016) illustrated the strategies of blended teaching model by taking an example from College English, and suggested that college English teachers should increase their knowledge and awareness of team cooperation in the course design.

b. Flipped classroom 
Wang (2015) discussed the feasibility of MOOCs and flipped classroom in College English teaching by analyzing the characteristics of Chinese college students and teachers. Hu \& Wu (2014) reported a College English teaching experiment on flipped classroom instruction based on self-developed College English MOOCs. It first analyzed the typical features of MOOCs and ways of incorporation into College English curriculum design and introduced the practical development of College English MOOCs and flipped classroom instruction. Quantitative and qualitative data collected from students showed that this MOOC-based flipped classroom instructional model is not only suitable for College English teaching, but also highly recognized by the students. Zhang \& Sun (2015) elaborated the significance and feasibility of implementing MOOC-based flipped classroom teaching model and suggested that construction of this teaching model can be done through four stages of frontal analysis, on-line activity design, classroom activity design and diverse assessment design. An eight-week tentative teaching experiments was conducted to find out its potential effects and possible problems. Bai (2016) conducted an empirical study on the multi-interactive teaching mode of College English, the results indicated that students' interests in English study and academic records have increased by multi-interactive teaching mode of micro-course online, MOOCs, social software and APP, etc..

(4). The changes to College English teachers

Jing et.al (2014) discussed the strategies young university teachers could take to face the fact of MOOCs' coming, and encouraged College English teachers to take part in MOOCs, pay more attention on the construction of experimental and practical platform and change the role of themselves during education. Li (2015) discussed teachers' teaching competence in the flipped classroom, it is required that teachers should play a key role to supervise, instruct and promote students' learning for the purpose of making full use of online resources before class. In the flipped classroom teachers are expected to participate much more in the learning process than they do in the traditional class. Teachers should not only focus on developing students' autonomous learning, but also design activities aim to develop their higher level of cognitive skills such as applying, analyzing, evaluating and creating. Chen (2016) explained the change of teacher-student relations from the following: teachers' teaching are no longer the only source of knowledge for students, they could get access to the same knowledge from autonomous online learning. This forces teachers to change their ideas, correct their understanding of the teacher authority, understand students and students' learning situation and make full use of teacher's leading role. There are three papers discuss College English teachers from the perspective of the ecology. Zhang \& Li (2016) re-positioned College English teachers' ecological niches from the perspective of the ecology and pointed out that they should meet the MOOCs' challenges from the following three aspect: changes of educational teaching ideas, changes of teachers' roles, the incorporation of traditional classroom and MOOCs. Hu (2016) discussed the issue of teachers' development with the emergence of MOOCs from the perspective of educational ecology. It explored College English teachers' impact on the whole educational ecosystem and the rules that govern their interaction in order to establish a balanced scientific educational ecosystem with multilateral participation. Ma (2015) discussed trend and position changes of College English teachers, particularly their relations with students, colleagues, textbooks, teaching methods and themselves. Facing MOOCs, it proposed the conception of College English teachers niche expansion so as to promote foreign language teaching compatible with dynamic and benign development of the ecological system.

\section{COLlege English COURSES ON MOOCs PlatFormS}

It seems that College English teaching has been greatly affected by the international wave of MOOCs from the previous review of papers published. Especially, the construction of College English content was heatedly discussed in the collected essays. All of the College English MOOCs made in Mainland China to show the practical College English Education at present.

TABLE I.

MOOCS' CONTENTS IN DIFFERENT MOOCS PLATFORMS IN MAINLAND CHINA

\begin{tabular}{|c|c|c|c|c|c|c|c|}
\hline \multirow{2}{*}{ MOOCs Platform } & \multicolumn{3}{|l|}{ EGP } & \multirow[t]{2}{*}{ ESP } & \multicolumn{2}{|l|}{ EGE } & \multirow{2}{*}{$\begin{array}{l}\text { Vocabular } \\
\text { y }\end{array}$} \\
\hline & $\begin{array}{l}\text { Speaking \& } \\
\text { Listening }\end{array}$ & $\begin{array}{l}\text { Reading } \\
\text { \& Writing }\end{array}$ & Translation & & Culture & Literature & \\
\hline xuetangx.com & 8 & 5 & & 3 & 3 & & \\
\hline CNMOOC & & 1 & & & $1 \mathrm{C}$ & & \\
\hline UOOC & 1 & 3 & & & $3+1 \mathrm{C}$ & & 1 \\
\hline WEMOOC & 1 & & 1 & & & & \\
\hline iCourse & 6 & 4 & & 3 & $2 \mathrm{C}$ & 2 & \\
\hline Total & 30 & & & 6 & 12 & & 1 \\
\hline
\end{tabular}

Note: $\mathrm{C}$ represents Chinese culture

From the Table.I, it can be seen that for some of the MOOCs platforms, such as xuetangx.com, there are nineteen courses about College English, among them thirteen courses are about EGP, speaking, listening, reading and writing, three cultural courses are part of EGE, and there are three ESP courses. For all of the five main MOOCs platforms in Mainland China, there are thirty-one courses delivering on language skills as EGP, although vocabulary is not one of the language skills it deals with basics, it is classified into EGP part. There are twelve courses about culture and 
literature belong to EGE, it is nice to see four courses introduce Chinese culture. Six courses are delivered as ESP. It can be seen obviously that more importance still has been attached to EGP courses.

\section{CONCLUSION}

The purpose of this study is to develop a systematic analysis of College English teaching reform under the impact of MOOCs by considering the articles published on CNKI. The data shows that College English reform in Mainland China has been affected by MOOCs on redesign of its teaching content, innovation of teaching model, College English teachers' professional requirements and their relationship with students. To be more precise, the content of College English is classified according to their course purpose, such as EGP courses, language skills of listening, speaking, writing and translation are mostly covered content in MOOCs. The College English teaching combines MOOCs online and flipped classroom teaching. This newly emerged way of teaching encourage College English teachers improve their own qualifications to meet the requirements. All of the previous descriptions are described in the papers collected, but in fact College English has not carried out MOOCs online teaching combined with flipped classroom or blended teaching. The problem lies that theoretically it seems the advanced technology could certainly improve College English teaching, but just a small part of universities try the new way of teaching, which is shown clearly in the MOOCs platforms about College English. Hopefully, there will be more practical College English MOOCs courses online and increasing number of qualitative study of College English MOOCs in CNKI.

\section{ACKNOWLEDGMENTS}

This research was supported by the China Scholarship Council; Soft Science Project of Henan Province 'Strategies for exporting cultural resources in Central Plains under the background of internet +: the establishment and research of the MSOC Talking Central Plains in English'. The 12th Five-year Plan of Henan Science of Education (2015JKGHYB-0063); The College Teaching Reform Project in Henan Polytechnic University (2015JG007; 2015JG086).

\section{REFERENCES}

[1] Alraimi, K. M., H. Zo \& A. P. Ciganek. (2015). Understanding the MOOCS continuance: the role of openness and reputation. Computers \& Education, 80, 28-38.

[2] Bai, Y. (2016). An Empirical Study on the Multi-Interactive Teaching Mode of University English in the Digital Environment Taking Lanzhou University of Finance and Economics as an Example. Journal of Heihe University, 5, 149-151. DOI: 10.3969/j.issn.1674-9499.2016.05.067 .

[3] Chen, C. M. (2016). Hulianwang shidai gaoxiao shisheng guanxi tantao: yi jiyu "muke"de fanzhuanketang weili. [Discuss on the teacher-student relationship in internet era: taking flipped classroom based on MOOCs for example]. Education Exploration. 6, 77-79.

[4] Chen, G. Q. \& W. W. Wang. (2016). Xinxihua jiaoxue huanjingxia "muke"yu chuantong daxueyingyu ketang jiehe de celue yanjiu. [On the strategies for the combination of "MOOCs" with traditional College English classroom teaching under the background of information-based teaching environment]. Journal of Mudanjiang University. 25. 02,163-165 \&175.

[5] Chen, W. C. (2016). An Analysis on Interfaces Between MOOCs and Foreign Language Teaching. Journal of China West Normal University: Philosophy \& Social Sciences. 5, 115-118. DOI:10.16246/j.cnki.51-1674/c.2016.05.017.

[6] DeWitt, D., S. Siraj \& N. Alias. (2014). Collaborative mLearning: A Module for Learning Secondary School Science. Educational Technology \& Society, 17. 1, 89-101.

[7] Dong, N. \& Y. A. Li. (2014). Muke jiaoyu dui xianyou yixueyingyushouke de qishi. [On the impact of MOOCs on the medical English teaching]. Shanxi Jiaoyu Gaojiao. 12, 39 \& 41. DOI:10.16773/j.cnki.1002-2058.2014.12.011.

[8] Graham, C. R. (2005). Blended learning systems: Definition, current trends, and future directions. In C. J. Bonk \& C. R. Graham (Eds.), Handbook of blended learning: Global perspectives, local designs (pp. 3-21). San Francisco: Pfeiffer Publishing.

[9] Graham, C. R., S. Allen\& D. Ure. (2003). Blended learning environments: A review of the research literature. Retrieved May 29, 2006, from http://msed.byu.edu/ipt/graham/vita/ ble_litrev.pdf.

[10] Han, Y. (2016). Yingyu tingli muke sheji yu gouxiang: yi "yingyu waitai xuanting" weili [on the design and construction of English listening MOOCs: Taking "listening news from VOA, BBC and CNN" for example]. Journal of Language and Literature Studies. 10, 105-106\&108.

[11] Higher Education Department of Education Ministry. (2007). College English Curriculum Requirements. Shanghai, China: Shanghai Foreign Language Education Press.

[12] Hu, J. H. \& Z. J. Wu (2014). An Empirical Study on the MOOC-based College English Flipped Classroom Instructional Model. Computer-assisted Foreign Language Education. 160, 40-45.

[13] Hu, Q. K. (2016). Daxueyingyujiaoshi fazhan de jiaoyu shengtai huanjing tantao: jiyu MOOCs shidai shiyuxia. [On the ecological environment of education for College English teachers' development: under the perspective of MOOCs era]. Journal of Chifeng University (Natural Science Edition). 32. 6, 264-265.

[14] Hutchison, T \& A. Waters. (1987). English for Specific Purposes: A Learning-Centred Approach. Cambridge, Cambridge University Press.

[15] Jing, L. D., J. Tan, X. L. Liu \& H. Li. (2014). Strategies for Young University Teachers in MOOC Times. The Science Education Article Collects. 292, 20-21.

[16] Kop, R. (2011). The challenges to connectivist learning on open online networks: Learning experiences during a massive open online course. The International Review of Research in Open and Distance Learning, 12. 3, 19-38. 
[17] Lei, Y. J. (2016). A Study of Blended English Teaching Method Based on Mooc for Higher Vocational College Students. Science \& Technology Vision. 9, 289\&303.

[18] Li, Y. (2015). A Study on Teachers' Teaching Competence in the Flipped Classroom. Foreign Languages in China. 12. 6, 1926. DOI:10.13564/j.cnki.issn.1672-9382.2015.06.004.

[19] Liu, X. Q. (2016). ESP kechengzhong jiyu MOOCs lilun de weike yingyong tanxi. [On the application of micro-lecture into ESP courses based on theory of MOOCs]. Journal of Suzhou Education Institute. 19. 5, 146-147 \& 172. DOI:10.13985/j.cnki.34-1227/c.2016.05.064.

[20] Ma, W. L. \& J. S. Hu. (2014). On the Impact of International MOOCs and Redesign of College English Curriculum. ComputerAssisted Foreign Language Education. 5, 48-54.

[21] Ma. H. (2015). Muke beijing xia daxueyingyujiaoshi shengtaiwei yanjiu. [On the ecological niche of College English teachers under the background of MOOCs]. Theory Research. 6, 241-244.

[22] Norman, H., R. Din, N. Nordin \& T. Ryberg. (2014). A review on the use and perceived effects of mobile blogs on learning in higher educational settings. Asian Social Science, 10. 1, 209-222.

[23] Ren, J. H. \& L. J. Guan. (2016). Muke shiyu xia minbangaoxiao ESPyingyu jiaoxue moshi yanjiu. [On the teaching model of ESP courses under perspective of MOOCs in private college]. Modern Communication. 9, 222-223.

[24] Sun, H. \& F. F. Wei. (2016). Jiyu muke he yuliaoku qudong de daxueyingyu hunheshi jiaoxue mushi yanjiu. [On College English blended teaching based on MOOCs and Corpus-driven]. Shandong Social Sciences. 6, 524-526. DOI:10.14112/j.cnki.37-1053/c.2016.s1.215.

[25] Sun, Q. (2016). Jiyu weikemoshi de daxueyingyu sijikaoshi fanyi jiaoxue sheji. [On the design of micro-lecture translation teaching for College English Test Band 4]. Crazy English Pro. 3, 65-67. DOI: 10.3969/j. issn. 1006-2831.2016.03.020.

[26] Sun, X. L. (2016). Jiyu "muke"pingtai fanyi nengli de peiyang[ On Cultivating translation skills based on MOOC platforms]. Shanghai Journal of Translators. 5, 73-76.

[27] Wang, J. (2016). College English Translation Teaching in the Era of MOOCs. Journal of Hubei Correspondence University. 29. 18, 124-125. DOI:10.3969/j.issn.1671-5918. 2016.18.059.

[28] Wang, L. (2015). Jiyu "muke" de "fanzhuanketang" mushi zai daxueyingyu jiaoxue zhong de chutan. [A tentative research on the model of "flipped classroom" in College English teaching based on "MOOCs"]. Journal of Higher Education. 9, 22-23.

[29] Wang, S. H., J. L. Liu \& W. P. Fu. (2015). A Study on the Content-based College ESP Instruction under the Background of MOOC Era. China Educational Technology. 4, 97-101.

[30] Wang, S. R. (2013). Jianchi kexuede daxueyingyu jiaoxue gaigeguan [Adhere to the science of legists in college English teaching]. Foreign Language World. 6, 9-22.

[31] Xie, G. P. (2015). MOOCs in College English Teaching: Prospects and Problems. Overseas English. 11, 33-35.

[32] Xiong, S. R. (2016). MOOCs' Effects on the Teaching of College English. Journal of Luoyang Normal University. 35. 9, 65-68. DOI:10.16594/j.cnki.41-1302/g4.2016.09.014.

[33] Yan, Y. (2014). Yingyu weike jiaoxue celue yanjiu. [On the teaching strategies of English micro-lectures]. Journal of Green Science and Technology. 12, 288-289.

[34] Zhang, D. E. (2015). Waiyu kouyu muke sheji yu shijian yanjiu: yi "muke yingyu 900 ju" weili. [Research on the design and practice of MOOCs for spoken English: taking "MOOC English 900 sentences" for example]. Foreign Language World. 4, 9096.

[35] Zhang, G. H. (2015). Muke gei daxueyingyu jiaoxue dailai de tiaozhan yu qishi. [The challenge and prospect brought by MOOCs to College English teaching]. Education Teaching Forum. 21, 188-189.

[36] Zhang, J. J. \& S. M. Li (2016). On the College Teachers' Ecological Niche under the Background of "MOOCs". Journal of Shanxi Datong University (Social Science). 30. 2, 85-87.

[37] Zhang, M. L. \& X. J. Sun (2015). MOOS-based Flipped Classroom Teaching Model for Follow-up College English Courses. Modern Education Technology. 25. 8, 81-87. DOI: 10.3969/j.issn.1009-8097.2015.08.012.

[38] Zhao, B. Y. \& J. Y. Wang. (2016). Muke dui ESP jiaoxue de yingxiang fenxi. [Analysis on the impact of MOOCs on ESP teaching]. Finance Theory and Teaching. 5, 83-85. DOI:10.13298/j.cnki.ftat.2016.05.019.

[39] Zhao, D. J. \& G. X. Shi. (2015). MOOCs and Reconstruction of College English Curriculum: The Perspective of Hidden Curriculum. Shandong Foreign Language Teaching.36. 5, 63-68. DOI:10. 16482/.sdwy37-1026.2015-05-009.

[40] Zhou, S. S. (2016). Hunhe jiaoxue shijiao xia de daxueyingyu jiaoxue zhi sikao. [Think about the College English teaching under the perspective of blended teaching]. Journal of Higher Education. 9, 109-110.

Min Cao was born in Anyang, Henan province, China in 1981. She received her Master Degree of Foreign Linguistics and Applied Linguistics from Southwest University, China in 2009.

She is currently a lecturer in Henan Polytechnic University, Jiaozuo, Henan Province, China. Her research interests include Second language Acquisition, English Language Teaching, and Intercultural Communication. 